\title{
Comparison of the Electromyographic Activity of Different Zones of the Abductor digiti minimi manus Muscle in Search of a Functional Compartmentalisation
}

\author{
Comparación de la Actividad Electromiográfica de Diferentes Zonas del Músculo \\ Abductor Digiti Minimi manus en Busca de una Compartimentación Funcional
}

Rodrigo Guzmán-Venegas ${ }^{1}$; Mikel Izquierdo ${ }^{2,4}$; Eduardo L. Cadore ${ }^{3}$ \& Juan Carlos López

GUZMÁN-VENEGAS, R.; IZQUIERDO, M.; CADORE, E. L. \& LÓPEZ, J. C. Comparison of the electromyographic activity of different zones of the Abductor digiti minimi manus muscle in search of a functional compartmentalisation. Int. J. Morphol., 39(2):441-446, 2021.

SUMMARY: There is evidence demonstrating the presence of functional compartmentalisation (FC) in some skeletal muscles. This means that the motor units (MU), grouped in certain areas of the muscle, show different levels of activation in comparison to those located in other zones. This has only been described in large muscles whose morphology proves the existence of a FC. However, there is no background information about small muscles, such as the Abductor digiti minimi manus (ADM). The objective of this study was to compare the activation of the MU in different zones of the ADM to support the hypothesis of the existence of a FC in the ADM. By using a crosssectional, analytical, observational study, the activity of the MUs in the ADM was assessed in 12 volunteers (age $21 \pm 1.6$ years old; weight $75.3 \pm 8 \mathrm{~kg}$; height $176.2 \pm 7.3 \mathrm{~cm}$; average \pm standard deviation). The activity of MUs was evaluated using high-density surface electromyography (HD-sEMG) with an array of 64 electrodes arranged two-dimensionally. This allowed us to record the activity of the MUs in three zones of the ADM (Z1: dorsal zone; Z2: dorsal-palmar zone and Z3: palmar zone). Electromyographic recordings were obtained during voluntary isometric contractions of the ADM at 20, 40, 60 and $80 \%$ of the maximum voluntary contraction (MVC). The comparison of the activation levels of MUs between the three zones was carried out using a mixed model analysis of covariance. The results showed a significant difference between the dorsal and palmar zones at $40 \%$ of the MVC $(p=0.03)$, and between the dorsal and dorsalpalmar zone at $80 \%$ of the MVC $(\mathrm{p}=0.03)$. The results obtained in the evaluated sample support the hypothesis of the existence of FC in the $\mathrm{ADM}$. However, further research is needed to determine with greater certainty the presence of this compartmentalisation in the ADM.

KEY WORDS: functional compartmentalisation, neuromuscular compartmentalisation; Abductor digiti minimi manus, highdensity surface electromyography.

\section{INTRODUCTION}

The Abductor digiti minimi of hand (ADM) is the most superficial of the muscles of the hypothenar eminence. Its origin is found in the pisiform bone, in the pisohamate and pisometacarpal ligaments, as well as in the tendon of flexor carpi ulnaris (Palastanga et al., 2002), some authors include the hamulus process of the hamatum and the palmar carpal ligament to this insertion (Gudemez et al., 2002). It is distally inserted in the ulnar region of the first phalanx of the little finger and in the dorsal digital expansion (Palastanga et al.), as well as in the dorsal expansion of the extensor digiti minimi muscle, the distal digital fascia and the skin at the level of the proximal interphalangeal joint (Soldado-Carrera et al., 2000; Gudemez et al.).

The ADM is innervated by the deep motor branch of the ulnar nerve, which passes across the muscle at an average distance of $31 \mathrm{~mm}$, distal to the proximal edge of the pisiform. From a morphological point of view, it has been recognised that the ADM consists of a single fusiform belly (Testut \& Latarjet, 1959; Murata et al., 2004). However, more recent studies have more frequently shown the presence of two bellies, one medial and other lateral (Santo Neto et

\footnotetext{
${ }^{1}$ Integrative Laboratory of Biomechanics and the Physiology of Effort, School of Kinesiology, Faculty of Medicine, Universidad de los Andes, Chile.

${ }^{2}$ Department of Health Sciences, Public University of Navarre, CIBER of Frailty and Healthy Aging (CIBERFES), Navarrabiomed, Pamplona, Navarre, Spain.

${ }^{3}$ School of Physical Education, Physiotherapy and Dance, Exercise Research Laboratory, Universidade Federal do Rio Grande do Sul, Porto Alegre, Brazil.

${ }^{4}$ GICAEDS Group, Physical Culture, Sports and Recreation Program, Universidad Santo Tomás, Bogotá, Colombia.

${ }^{5}$ Department of Morphology, Faculty of Medicine, Universidad de los Andes, Chile.
} 
al., 1984; Buarque de Gusmão et al., 2005), the latter being the most superficial (Gudemez et al.).

The action of the ADM involves abduction of the little finger and flexion of the metacarpophalangeal joint. Due to its proximity to the dorsal digital expansion, the ADM is a synergist muscle in the extension of the interphalangeal joint. In addition, this muscle plays an important role in grasping large objects when the fingers are extended (Palastanga et al.).

The action of the ADM, as a whole muscle, lies in the activation of its motor units (MUs). In this context, there are electromyographic (EMG) studies that demonstrate the existence of heterogeneity in the recruitment of MUs, which is dependent on their specific location within the muscle and on the characteristics of the motor task performed. This heterogeneity in activation has led to the hypothesis that certain muscles could be organised neuromuscularly as functional compartments (FC), beyond the existence that is demonstrable at a morphological level. This would imply that the MUs grouped in certain muscle regions would show different activation levelsthat differ from the MUs located in other zones of the same muscle (Brown et al., 2007). In this sense, several studies have demonstrated the existence of this neuromuscular compartmentalisation (NMC). Staudenmann et al. (2009) recorded the differential activation of the different regions of the triceps surae, in relation to foot movements and the direction of the ground reaction force (GRF). Moreside et al. (2008) demonstrated the existence of differential recruitment of the upper and lower portions of the rectus abdominis muscle in different low intensity-exercises. While studying the recruitment of different regions of the rectus femoris in exercises combining hip flexion and knee extension, Watanabe et al. (2012) demonstrated the presence of at least two regions with differential recruitment, so that two NMC were identified. Later, Guzmán-Venegas et al. (2015) demonstrated the existence of three FCs in the superficial masseter muscleduring submaximal bite-force magnitudes.

The relatively large size, and the association with gross motor tasks are characteristicof the muscles that have been the subject of study in the search for their NMC. On the contrary, the intrinsic muscles of the hands have not been subject of studies in the search of possible NMCs, as these muscles are seen to be small and associated with quite fine tasks, implying that their motor units are relatively small (Santo Neto et al., 1998). For this reason, it is of interest to test the hypothesis of the existence of possible FC in muscles with these characteristics. The objective of this study was to compare the activation of the MUs in different zones of the ADM in order to support the hypothesis of the existence of a FC in this muscle.

\section{MATERIAL AND METHOD}

By using a cross-sectional, analytical, observational study (Hernández Sampieri et al., 2014), a sample of 12 healthy volunteers (age $21 \pm 1.6$ years old; weight $75.3 \pm$ $9.8 \mathrm{~kg}$; height $176.2 \pm 7.3 \mathrm{~cm}$; average \pm standard deviation) was evaluated. The following exclusion criteria were applied in the recruitment of volunteers: i.- history of musculoskeletal injuries to the upper limbs in the past 6 months (for example, fracture, muscle tear, sprain, etc.); ii.- history of both central and peripheral neurological conditions or diseases; iii.consumption of substances such as alcohol and/or drugs in the previous 24 hours; iv.- habitual practice of sports that involve the use of the muscles of the hand (for example, climbing, judo, etc.); v.- use of psychotropic drugs in the past 6 months (e.g. olanzapine, risperidone, quetiapine, droperidol, clonazepam, sertraline, etc.). All volunteers gave written consent by signing an informed consent document. All procedures in this study were in accordance with the criteria of the Declaration of Helsinki and were approved by the local ethics committee (Date of approval: 2018-1505 code: SCEC201824).

Procedure. All assessments were performed in a laboratory environment. Each volunteer was asked to sit in a chair in front of a table, on which a specially designed device was placed to placethe hand and part of his/her forearm (Fig. 1A). Throughout the assessment, the elbow was kept in a $90^{\circ}$ flexion position. In the device, a force sensor (3E151/ 014, Kinetecnics, Santiago de Chile, Chile) was installed to assess the isometric force developed by the ADM (Fig. 1B). Likewise, the device allowed for the installation of a matrix of 64 surface EMG electrodes (ELSCH064NM5, OT Bioelettronica, Torino, Italy) which was arranged in 4 rows of 13 electrodes each, and one row of 12 electrodes (Fig. 1C).This allowed us to record the electrical activity of the MUs in the different zones of the ADM. The electrode array was placed on the ADM, in a way that its rows were arranged parallel to the muscle fibres. In the first instance, the maximum voluntary isometric contraction (MVIC) of the ADM was assessed using the force sensor. Each volunteer was asked to perform three maximal contractions of the ADM, lasting four seconds, with one minute of rest between them. From these three recordings the maximum value was determined, and that was considered the MVC (GuzmánVenegas et al.).

Prior to EMG recordings, the skin on the ADM was cleaned with an abrasive paste (Everei, Spes Medica, Battipaglia, Italy), in order to reduce the skin impedance. The recorded tests consisted of performing submaximal voluntary isometric contractions of the ADM, equivalent to 


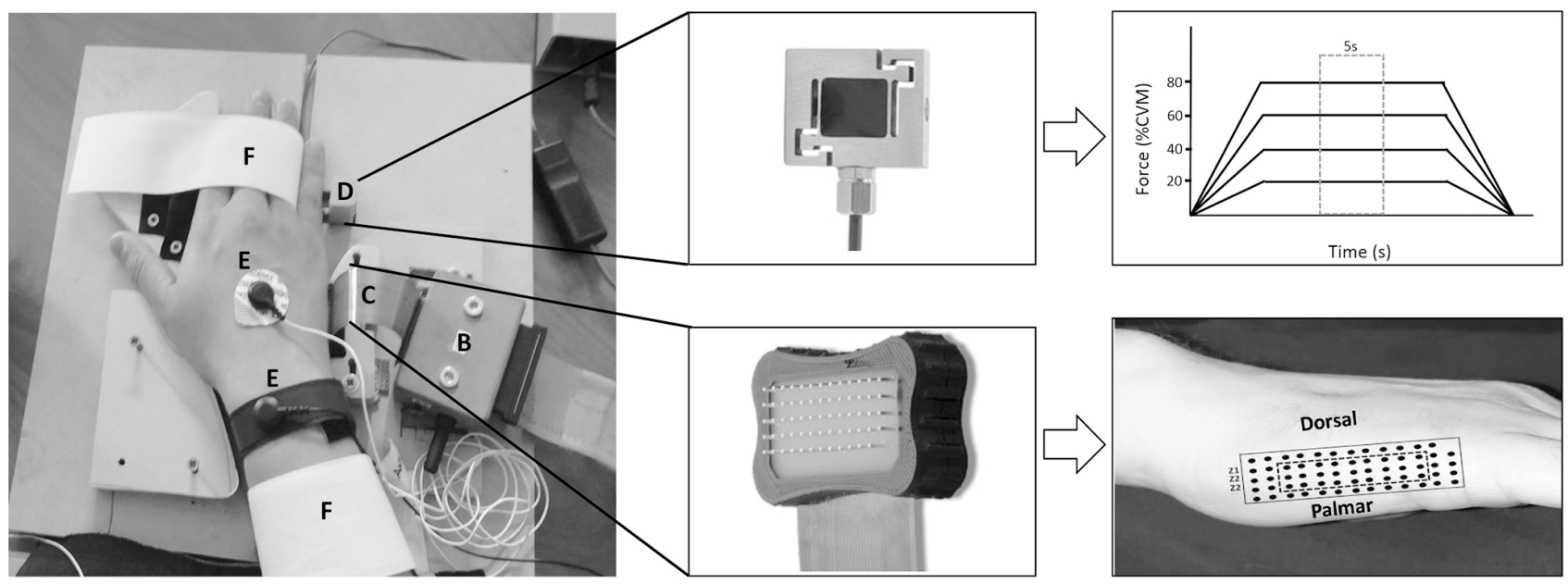

Fig. 1. Mounting details for electromyographic records of abductor digiti minimi manus(ADM).General view of set-up for measuring the activity of the motor units (MU) of ADM (1A), components of set-up: High-density electromyographic signal preamplifier(B). 64electrode surface electromyography (sEMG) matrix (C). Force sensor(D). Reference electrode and cuff for electromyographic amplification(E). Velcro fastening for wrist and fingers (F).

Mounting sensors: force sensor used to measure the isometric force of the ADM(1B). Recording electrode matrix, (1C) detail of the arrangement of the 64s EMG electrodes. Graph used to control the force of the ADM, (1D) force paradigms performed by the volunteers at levels of 20, 40, 60 and $80 \%$ of maximum voluntary contraction (MVC). Location of the electrode array on the ADM(1E). The zone has been highlighted with the red dashed line, and the electrodes that were used in the analysis of the MUs activity. The designation of recording zones are Z1: dorsal zone; Z2: dorsal-palmar zone and Z3: palmar zone.

20, 40, 60 and $80 \%$ of the MVC, which were conducted following a pre-established paradigm (Fig. 1D). The magnitude of the contractions was controlled by visual feedback from the ADM force record, which was superimposed over the paradigms, and both were graphed in real time on a screen located in front of the volunteer. There was a break of five minutes between each test, and their order of execution was randomly determined. Before the final recording, testing samples were carried out at $50 \%$ of the MVC in order to familiarise the volunteer with the procedure. The EMG signals were recorded using highdensity EMG equipment (EMG-USB2, OT-Bioelettronica, Torino, Italy), and they were amplified in a monopolar manner with a gain factor of 500 units. The signals were digitised with a sampling frequency of $2048 \mathrm{hz}$ in a bandwidth from 10 to $500 \mathrm{hz}$ (Guzmán-Venegas et al.). A synchronised capture of both EMG and force sensor signals was made, which were stored usingdata collection software (OtBiolab version 2.6, OP Bioelettronica, Torino, Italy).

EMG signal processing. EMG data, corresponding to the central 5 seconds of each test (Fig. 1D), were processed in order to consider data in a stable state. For the analysis of the signals, the outermost rows of the matrix were not considered in the analysis. Similarly, the most proximal and distal channelswere not considered in the analysis. The foregoing was decided in order that the processed signals were found with greater certainty within the anatomical territory of the ADM. The 27 monopolar signals considered in the analysis were differentiated in the direction of the matrix rows (Z1, Z2 and $\mathrm{Z} 3$ ), thus, each row had 8 differential EMG signals ( 24 in total). Then, the amplitude of the signals was assessed calculated using the root mean square (RMS), using a 250 milliseconds window. Thus, for each signal, 20 RMS amplitude values were obtained corresponding to the 5 seconds of analysis. Therefore, for each row, a total of 160 RMS values were obtained. To represent the activity of the MUs of each row, and thus of the different regions of the ADM, the medianof the 160 values was considered. The rows were assigned according to their location in the ADM, as follows: Z1: dorsal zone; Z2: dorsal-palmar zone, and Z3: palmar zone, as shown in Figure 1E.

Statistical analysis. Initially, a descriptive statistics analysisof the activation levels of the different zones of the ADM was carried out. The comparison of the activation levels of the MUs recorded in the different dorsal, dorsalpalmar and palmar zones (Z1, Z2 and Z3, respectively) was carried out through a mixed model analysis of covariance (Littell et al., 2006). All statistical analyses were carried out in two tails and with a statistical significance level of $95 \%$. Statistically significant differences were those associated with a p-value $<0.05$. All analyses were performed usingstatistical analysis software (STATA/SE 12.1. Stata Corp. College Station, USA). 


\section{RESULTS}

The EMG amplitudes recorded in the three zones of the ADM (Z1, Z2 and Z3) at the different contraction levels are shown as averages and standard deviation in Table I. At the contraction levels of 20 and $60 \%$ MVC, no significant differences between the three zones were observed. At $40 \% \mathrm{MVC}$, the dorsal zone (Z1) showed greater activity than the palmar zone $(\mathrm{Z} 3)(\mathrm{p}=0.039)$. Similarly, at $80 \% \mathrm{MVC}$, the

Table I. Comparison of the normalised electromyographic amplitude between three zones (Z1, Z2 and Z3) of the abductor digiti minimi (ADM) muscle, during contractions at different levels. The amplitudes are shown as averages (standard deviation) of the EMG amplitude adjusted to the MVC.

\begin{tabular}{lllll}
\hline$\% \mathrm{MV}$ & $(\mathrm{Z1})$ & $(\mathrm{Z} 2)$ & $(\mathrm{Z})$ & Inter-regional \\
\hline $20 \%$ & $27.1(20.8)$ & $24.4(12.5)$ & $23.0(9.4)$ & None \\
$40 \%$ & $54.9(31.7)$ & $52.4(30.6)$ & $48.7(22.0)$ & $\mathrm{Z} 1>\mathrm{Z} 3 \dagger$ \\
$60 \%$ & $66.0(22.7)$ & $68.2(25.9)$ & $64.5(15.9)$ & None \\
$80 \%$ & $94.6(37.6)$ & $78.3(21.7)$ & $79.5(22.7)$ & $\mathrm{Z} 1>\mathrm{Z} 2 \dagger$ \\
\hline
\end{tabular}

MVC: Maximum voluntary contraction.

$\dagger \mathrm{P}$-value $<0.05$ in mixed model analysis.

$\mathrm{Z} 1$ : dorsal zone; Z2: dorsal-palmar zone and Z3: palmar zone.

\section{DISCUSSION}

The results of this research show that at certain levels of muscle contraction ( 40 and $80 \%$ MVC) the dorsal, dorsal-palmar and palmar zones of the ADM show differences in the recruitment of the MUs located in these zones, which could support the hypothesis of the existence of a functional or neuromuscular compartmentalisation of the ADM.

While it is true that the ADM has been the subject of previous electrophysiological studies (Farina et al., 2008; Bouillard et al., 2012), to date, these studies have not focused on examining the heterogeneity in the recruitment of the MUs. The results of the present study bring to light the possible existence of a FC; however, the results are not categorical, since at certain levels of contraction (20 and $60 \% \mathrm{MVC}$ ), differences in the recruitment of MUs are not demonstrated.In this study, the activity of the MUs was examined, considering three zones: dorsal, dorsal-palmar and palmar (Z1, Z2 and Z3, respectively), which were divided according to the fusiform morphology of the ADM. From a mechanical perspective, it is difficult to justify the presence ofdifferential activation of the MUs in different zones of a muscle whose fibres fusiformly converge to a single tendon. In comparison with another type of morphology — such as that of the masseter muscle - this turns out to be more justifiable, given that it dorsal zone showed greater activity than the dorsal-palmar zone $(\mathrm{p}=0.037)$ and there was a tendency for the dorsal zone to have greater activity than the palmar zone ( $\mathrm{p}=0.053)$. Pvalues of all comparisons are presented in Table II.

Table II. P-values calculated from the comparison made using the mixed model analysis of covariance.

\begin{tabular}{cccc}
\hline \% MVC & & $(\mathrm{Z} 1)$ & $(\mathrm{Z3})$ \\
\hline \multirow{2}{*}{20} & $(\mathrm{Z} 1)$ & -- & 0.224 \\
& $(\mathrm{Z} 2)$ & 0.427 & 0.673 \\
40 & $(\mathrm{Z} 1)$ & -- & $\mathbf{0 . 0 3 9}$ \\
& $(\mathrm{Z} 2)$ & 0.407 & 0.216 \\
60 & $(\mathrm{Z} 1)$ & -- & 0.791 \\
& $(\mathrm{Z} 2)$ & 0.716 & 0.530 \\
80 & $(\mathrm{Z} 1)$ & -- & 0.053 \\
& $(\mathrm{Z} 2)$ & $\mathbf{0 . 0 3 7}$ & 0.881 \\
\end{tabular}

MVC: Maximum voluntary contraction $\dagger \mathrm{P}$-value $<0.05$ in mixed model analysis. Z1: dorsal zone; Z2: dorsal-palmar zone and Z3: palmar zone. has multiple insertion sites in the jaw, which suggests functional differences between the MUs of its different portions. Indeed, the existence of a FC has been evidenced in this muscle, using a fundamentally mechanical rationale (Guzmán-Venegas et al.). However, there is background information about muscles with a single tendon in which the behaviour of their MUs describes the existence of a FC. Blanksma et al. (1997) demonstrated the heterogeneous recruitment of MUs from the temporalis muscle in humans during different chewing tasks. Furthermore, Wickham \& Brown (2012) showed the existence of a FC in the pectoralis major and latissimus dorsi muscles, in relation to different movements of the shoulder. Likewise, Méndez et al. (2013) reported the existence of three functional compartments in the fibularis longus muscle.

The presence of the differential recruitment pattern between the three zones recorded in the ADM could have a morphological substrate related to the three motor branches emerging from the motor branch of the ulnar nerve that innervate the ADM (Gudemez et al.). Possibly, each of these motor branches could innervate the muscle fibres located in the areas studied; however, the corroboration of this assumption should be done with histochemical and/or stereoscopic studies. 
The differential recruitment of the MUs could be attributed to their different properties. It is well known that MUs have different metabolic and mechanical properties, which differentiate them in terms of size, rate of force production, resistance to fatigue and activation threshold, classifying them into fast, fast-slow and slow motor units (Burke et al., 1971; McDonagh et al., 1980). In general, the fast MUs turn out to be large with a high activation threshold and low resistance to fatigue, while the slow ones are smaller in diameter with a low activation threshold, and they are more resistant to fatigue (Henneman et al., 1965). On the other hand, it has been described that the distribution of the different types of MUs within a muscle proves to be heterogeneous, in which a greater amount of MU of a certain type is concentrated in certain regions (Korfage \& Van Eijden, 1999; Rainoldi et al., 2000). For this reason, the differences in the activation levels of the MU of the three zones studied could be attributed to the heterogeneous distribution of the MU type within the ADM. The results indicate that the MUs located in the dorsal zone of the ADM showed greater activation than the MUs of the dorsal-palmar and palmar zones, being significant at 40 and $80 \%$ of the MVC. The foregoing could be interpreted as a higher concentration of slow MUs in this area, since this type of MU shows a lower activation threshold; however, this needs to be analysed by histochemical studies.

Within the limitations of this study is the fact of studying the activity of MUs of the ADM only in the main motor function of the ADM. Future research should consider, in addition to the abduction, the flexion component of the metacarpophalangeal joint, as well as functional tasks such as grasping.

\section{CONCLUSION}

The results obtained in the evaluated sample support the hypothesis of the existence of functional compartmentalisation in the ADM. However, further research is needed to determine with greater certainty the topographic behaviour of the MUs of the ADM.

\section{ACKNOWLEDGEMENTS}

The authors would like to thank Álvarez C., Bernasconi J., Campos S., Guzmán J. y, Hasbún A. for their technical collaboration during data collection of this study.
GUZMÁN-VENEGAS, R.; IZQUIERDO, M.; CADORE, E. L. \& LÓPEZ, J. C. Comparación de la actividad electromiográfica de diferentes zonas del músculo abductor digiti minimi manus en busca de una compartimentación funcional. Int. J. Morphol., 39(2):441-446, 2021.

RESUMEN: Existe evidencia que demuestra la presencia de una compartimentalización funcional (CF) en algunos músculos esqueléticos. Aquello se traduce en que las unidades motoras (UM) agrupadas en ciertas zonas del músculo, presentan diferentes niveles de activación a las ubicadas en otras regiones. Esto solo ha sido descrito en músculos grandes, cuya morfología justifica la existencia de una CF. Sin embargo, no existen antecedentes de aquello en músculos pequeños, tales como el abductor digiti minimi manus (ADM). El objetivo de este estudio fue comparar la activación de las UM en distintas zonas del ADM, con la finalidad sostener la hipótesis de la existencia de una CF en el ADM. Mediante un estudio observacional analítico transversal se evaluó la actividad de las UM del ADM en 12 voluntarios (edad 21 $\pm 1,6$ años; peso 75,3 \pm 8 $\mathrm{kg}$; altura 176,2 $\pm 7,3 \mathrm{~cm}$; promedio \pm desviación estándar). La actividad de las UM, se evaluó mediante electromiografía de superficie alta densidad usando una matriz de 64 electrodos dispuestos bidimensionalmente. Esta permitió registrar la actividad de las UM en tres zonas del ADM (Z1: zona dorsal; Z2: zona dorso-palmar y Z3: zona palmar). Los registros electromiográficos fueron obtenidos durante contracciones isométricas voluntarias del ADM al 20, 40, 60 y $80 \%$ de la contracción voluntaria máxima (CVM). La comparación de los niveles de activación de las UM entre las tres zonas fue realizada mediante un análisis de modelos mixtos de covarianza. Los resultados indicaron que existió diferencia significativa entre la zona dorsal y palmar al $40 \%$ de la CVM $(\mathrm{p}=0,03)$, y entre la zona dorsal y dorso-palmar al $80 \%$ de la CVM ( $\mathrm{p}=0,03)$. Los resultados obtenidos en la muestra evaluada sostienen la hipótesis de la existencia de una CF en el ADM. Sin embargo, son necesarias más investigaciones para establecer con mayor certeza la presencia de esta compartimentalización en el ADM.

PALABRAS CLAVE: Compartimentalización funcional; Compartimentalización neuromuscular; Abductor digiti minimi; Electromiografía de alta densidad.

\section{REFERENCES}

Blanksma, N. G.; van Eijden, T. M.; van Ruijven, L. J. \& Weijs, W. A. Electromyographic heterogeneity in the human temporalis and masseter muscles during dynamic tasks guided by visual feedback. J. Dent. Res., 76(1):542-51, 1997.

Bouillard, K.; Hug, F.; Guével, A. \& Nordez, A. Shear elastic modulus can be used to estimate an index of individual muscle force during a submaximal isometric fatiguing contraction. J. Appl. Physiol. (1985), 113(9):1353-61, 2012.

Brown, J. M. M.; Wickham, J. B.; McAndrew, D. J. \& Huang, X. F. Muscles within muscles: Coordination of 19 muscle segments within three shoulder muscles during isometric motor tasks. J. Electromyogr. Kinesiol., 17(1):57-73, 2007.

Buarque de Gusmão, L. C.; FrassyFeijó, M. J. \& de Sousa-Rodrigues, C. F. Morphologic aspects of abductor digiti minimi muscle in the hand. Int. J. Morphol., 23(4):373-6, 2005. 
Burke, R. E.; Levine, D. N. \& Zajac 3rd, F. E. Mammalian motor units: physiological-histochemical correlation in three types in cat gastrocnemius. Science, 174(4010):709-12, 1971.

Farina, D.; Negro, F.; Gazzoni, M. \& Enoka, R. M. Detecting the unique representation of motor-unit action potentials in the surface electromyogram. J. Neurophysiol., 100(3):1223-33, 2008.

Gudemez, E.; Tekdemir, I.; Uslu, M.; Eksioglu, F. \& Elhan, A. Innervation pattern of the abductor digiti minimi muscle of the hand. J. Hand Surg. Br. Eur. Vol., 27(5):435-9, 2002.

Guzmán-Venegas, R. A.; Biotti Picand, J. L. \& Berral de la Rosa, F. J. Functional compartmentalization of the human superficial masseter muscle. PLoS One, 10(2):e0116923, 2015.

Henneman, E.; Somjen, G. \& Carpenter, D. O. Excitability and inhibitability of motoneurons of different sizes. J. Neurophysiol., 28(3):599-620, 1965.

Hernández Sampieri, R.; Fernández Collado, C. \& Baptista Lucio, P. Metodología de la Investigación. $6^{\text {th }}$ ed. Ciudad de México, McGraw-Hill Education, 2014.

Korfage, J. A. M. \& Van Eijden, T. M. G. J. Regional differences in fibre type composition in the human temporalis muscle. J. Anat., 194(Pt. 3):355-62, 1999.

Littell, R. C.; Milliken, G. A.; Stroup, W. W. \& Wolfinger, R. D. SAS System for Mixed Models. Cary (N. C.), SAS Institute Inc., 1996.

McDonagh, J. C.; Binder, M. D.; Reinking, R. M. \& Stuart, D. G. A commentary on muscle unit properties in cat hindlimb muscles. $J$. Morphol., 166(2):217-30, 1980.

Méndez, G. A.; Gatica, V. F.; Guzmán, E. E. \& Soto, A. E. Evaluation of the neuromuscular compartments in the peroneus longus muscle through electrical stimulation and accelerometry. Braz. J. Phys. Ther, 17(5):42734, 2013.

Moreside, J. M.; Vera-Garcia, F. J. \& McGill, S. M. Neuromuscular independence of abdominal wall muscles as demonstrated by middleeastern style dancers. J. Electromyogr. Kinesiol., 18(4):527-37, 2008.

Murata, K.; Tamai, M. \& Gupta, A. Anatomic study of variations of hypothenar muscles and arborization patterns of the ulnar nerve in the hand. J. Hand Surg. Am., 29(3):500-9, 2004.

Palastanga, N.; Field, D. \& Soames, R. Anatomy and Human Movement. Structure and Function. $4^{\text {th }}$ ed. Boston, Butterworth-Heinemann, 2002.

Rainoldi, A.; Nazzaro, M.; Merletti, R.; Farina, D.; Caruso, I. \& Gaudenti, S. Geometrical factors in surface EMG of the vastus medialis and lateralis muscles. J. Electromyogr. Kinesiol., 10(5):327-36, 2000.

Santo Neto, H.; de Carvalho, V. C. \& Marques, M. J. Estimation of the number and size of human flexor digiti minimi muscle motor units using histological methods. Muscle Nerve, 21(1):112-4, 1998.

Santo Neto, H.; de Carvalho, V. C. \& Penteado, C. V. Morphological and architectural aspects of the Abductor digiti minimi. Okajimas Folia Anat. Jpn., 60(6):389-400, 1984.

Soldado-Carrera, F.; Vilar-Coromina, N. \& Rodríguez-Baeza, A. An accessory belly of the abductor digiti minimi muscle: a case report and embryologic aspects. Surg. Radiol. Anat., 22(1):51-4, 2000.

Staudenmann, D.; Kingma, I.; Daffertshofer, A.; Stegeman, D. F. \& van Dieën, J. H. Heterogeneity of muscle activation in relation to force direction: a multi-channel surface electromyography study on the triceps surae muscle. J. Electromyogr. Kinesiol., 19(5):882-95, 2009.

Testut, L. \& Latarjet, A. Tratado de Anatomía Humana. $9^{\text {th }}$ ed. Barcelona, Salvat, 1959.

Watanabe, K.; Kouzaki, M. \& Moritani, T. Task-dependent spatial distribution of neural activation pattern in human rectus femoris muscle. J. Electromyogr. Kinesiol., 22(2):251-8, 2012.

Wickham, J. B. \& Brown, J. M. M. The function of neuromuscular compartments in human shoulder muscles. J. Neurophysiol., 107(1):336-45, 2012.
Corresponding author:

Rodrigo Guzmán-Venegas

Avenida Monseñor Álvaro del Portillo 12.455

Las Condes

Santiago - RM

CHILE

E-mail: rguzman@uandes.cl

Received: 02-10-2020

Accepted: 26-11-2020 